\title{
Progressive familial intrahepatic cholestasis
}

\section{in children}

\author{
Eylem Sevinc ${ }^{1 *}$; Mehmet Agin ${ }^{2}$; Erkan Dogan ${ }^{3}$ \\ ${ }^{1}$ Department of Pediatric Gastroenterology, Karabuk University, School of Medicine, Karabuk, Turkey \\ ${ }^{2}$ Department of Pediatric Gastroenterology, Health Science University, Van Training and Education Hospital, Van, Turkey \\ ${ }^{3}$ Department of Pediatrics, Karabuk University, School of Medicine, Karabuk, Turkey
}

\section{*Corresponding Author(s): Eylem Sevinc,}

Department of Pediatric Gastroenterology, Karabuk

University, School of Medicine, Turkey

Email: dr.eylemsevinc@gmail.com

Received: Feb 19, 2018

Accepted: Mar 23, 2018

Published Online: Apr 06, 2018

Journal: Annals of Gastroenterology and the Digestive System

Publisher: MedDocs Publishers LLC

Online edition: http://meddocsonline.org/

Copyright: (C) Sevinc E (2018). This Article is distributed

under the terms of Creative Commons Attribution 4.0

International License

Keywords: Cholestasis; Mutation; Byler's Disease

\section{Introduction}

PFIC is an autosomal recessive disorder of cholestasis. Incidence is estimated to be at 1: 50,000 to $1: 100,000$ births. In this disease, cholestasis and hepatocellular damage is caused by a defect in bile acid transport. The onset of the disease is generally infancy but diagnosis may be delayed until adolescence. It is shown that 3 genes are responsible for the PFIC disease [1].

\section{PFIC1- Byler Disease}

PFIC1, also known as Greenland familial cholestasis, is caused by a mutation in the ATP8B1 gene (FIC 1) localized in the chromosome 18 (18q21). The protein produced by ATP8B1 gene is found throughout the body. Mutations in the ATP8B1 gene causes bile accumulation in hepatocytes. It is not known exactly how the mutation of this gene causes cholestasis short stature and deafness [2].

\section{Abstract}

Progressive familial intrahepatic cholestasis (PFIC) is a chronic condition that begin in childhood and leads to cirrhosis and liver failure in the first years of life. It can be difficult to distinguish from other forms of cholestatic liver diseases. Treatment of PFIC includes medical and surgical methods. This study aimed to review PFIC in light of the recent studies.

\section{PFIC2}

PFIC2 is similar to Byler's disease clinically. It is caused by a mutations in ABCB11. Mutations of this gene result dysfunction in the bile salt export pump (BSEP). Recently, The ABCB11 gene, also know sister-glycoprotein (SPGP) has been shown to be localized chromosome $2 q 24$ (3). More than 80 different mutations in $A B C B 11$ gene have been reported in patients with PFIC2 (4).

\section{PFIC3}

Mutations in the $A B C B 4$ gene encoding the MDR3 protein causes PFIC3 disease. MDR3 plays an important role in the transport of phosphatidylcholine through the canal. Mutations in $A B C B 4$ gene result deterioration of bile transport. Phospholipid deficiency, which leads to cholestasis produces unstable micelles having a toxic effect on bile duct [5].

Cite this article: Sevinc E, Agin M, Dogan E. Progressive familial intrahepatic cholestasis in children. Ann Gastroenterol Dig Syst. 2018; 1: 1003. 
Signs and symptoms

Children with PFIC manifest with jaundice, poor weight gain and pruritus. The onset of symptoms vary with each type. PFIC1 is characterized by recurrent cholestasis episodes with intractable pruritus and diarrhea. Symptoms of PFIC1 usually begin between the $3^{\text {rd }}$ and $6^{\text {th }}$ months of life. It usually leads to liver failure and cirrhosis within the first years of life. Other features include sensorineural hearing loss, chronic diarrhea, cholecystitis, recurrent pancreatitis, cough and delayed puberty development $[5,6]$.

The progression of PFIC2 is considered to be more severe than PFIC1. Patients generally present with jaundice at onset. Affected patients also have an increased risk of developing hepatocellular carcinoma and end-stage liver failure. If the liver is not transplanted, death is inevitable. Cholelithiasis has been reported in patients with PFIC2. Unlike PFIC1, extrahepatic symptoms are not present in PFIC2 $[7,8]$.

PFIC3 is rarely seen in the first year of life with clinical signs of cholestasis. Older children may have features of portal hypertension, including gastrointestinal bleeding and splenomegaly. The intensity of pruritus and jaundice in PFIC3 is less severe than other PFIC types. Just like PFIC2, Cholelithiasis has also been reported in patients with PFIC3. Progression to end-stage liver disease is generally slow $[9,10]$

\section{Diagnosis}

The diagnosis of PFIC is based on clinical, radiological, biochemical, histopathologic and ultrastructural findings [5]. Abdominal ultrasonography examination should be performed to exclude bile duct diseases. In patients with PFIC, ultrasonography is normal. In some PFIC types, biliary stones may also be detected. When performed, cholangiography may show a normal biliary tree $[5,11]$.

\section{Biochemistry}

Although serum bilirubin measurement is not a reliable indicator of cholestasis, it is an important test in the initial phase. A detailed liver function and coagulation tests, especially gamma glutamyl transferase (GGT) measurement are required in all patients. The low GGT concentrations indicates PFIC1-2 while high concentrations would be seen in PFIC3. Further within the PFIC spectrum, serum bile acid levels are grossly elevated. On the other hand serum cholesterol levels are not elevated. Other tests include metabolic screening and serologic tests $[12,13,14]$.

\section{Histopathological changes}

PFIC1 biopsies are typically characterized by a maintained lobular architecture without inflammation. Canalicular bile is pale or wispy. The interlobular bile ducts are hypoplastic. Ducytopenia is often seen. Lobular fibrosis and cirrhosis develop later in the course of the disease $[5,10,12]$.

PFIC2 is seen a canalicular and hepatocellular cholestasis with khaki-colored bile. Although giant cell hepatitis with lobular inflammation and hepatocellular necrosis is predominant, true ductular proliferation is absent $[12,15]$.

PFIC3 biopsies show evidence of true ductular proliferation with mixed inflammation and portal fibrosis [5,12].

\section{Liver immunostaining}

MDR3 and BSEP immunostaining in liver tissues would be a helpful component in differentiating not only PFIC from other causes of neonatal cholestasis but also subtypes of PFIC [16].

\section{Mutational analysis}

The diagnosis of PFIC may confirmed by mutation analysis of the ATP8B1, ABCB11 and ABCB4 gene. Insertion, deletion, nonsense, and splicing mutations of the implicated genes result in damaging effects. Detection of biallelic mutations is accepted as diagnostic $[17,18,19]$.

\section{Differential diagnosis}

Differential diagnosis varies with the age of presentation. It must be differentiated from other causes of cholestasis. Serum GGT measurement is very useful to observe cholestasis. Serum GGT concentrations is normal or low in PFIC1-2, on the other hand it is typically elevated in PFIC3 and other common causes of neonatal cholestasis like biliary atresia, alagille syndrome, alpha 1 antitrypsin deficiency. Bile acid synthesis disorders (BASDs) are a group of rare metabolic disorders which present with cholestasis and normal GGT. The serum bile acid concentration is low or absent in BASDs. On the other hand the serum bile acid concentration is high levels in PFIC1-2. Urinary bile acid analysis is required for diagnosis of BASDs. Neonatal hemochromatosis, familial amish hypercholanemia and arthrogryposis-renal dysfunction syndrome (ARC syndrome) are a rare cholestatic diseases with normal GGT $[12,20]$.

\section{Treatment}

Medical and surgical methods are used to treat of PFIC patients. Medical therapy includes choleretic drugs and nutritional support [21]. Pruritis is an important problem in children with cholestasis. Choleretic drugs such as ursodeoxycholic acid (UDCA), rifampicin and cholestyramine are used in the treatment [22].

CYP3A4 which is a major cytochrome P450 plays a critical role in the detoxification of bile acids and also increases conjugation and excretion of bilirubin. Rifampicin reduces pruritus by inducing the expression of CYP3A4 in the biotransformation of bile acids. The dosage is $10-20 \mathrm{mg} / \mathrm{kg} /$ day PO in two divided doses [25]. Cholestyramine binding bile salts in the intestinal tract increases fecal bile salt excretion. However it has not been showed to be useful in children with PFIC1-2. The recommended dose of cholestyramine is $240 \mathrm{mg} / \mathrm{kg} / \mathrm{day} \mathrm{PO}$, in three divided doses [26].

Engelmann et al. proposed steroid treatment has a positive effect on disease course of PFIC 2 [27]. Recently new choleretic agents such as resveratrol, retinoid $X$, farnesoid $X$ receptor agonists and tauroursodeoxycholate are investigated in the treatment of cholestasis. However those are still in the experimental phase $[28,29,30]$.

Nutritional support includes water and fat soluble vitamins, medium chain triglycerides (MCT oil), calcium and zinc supplementation. The total dietary energy intake should be $125 \%$ of recommended daily allowance. Children with cholestasis should be intake daily vitamin A- 5000-25,000 IU, vitamin D 400-800 $\mathrm{IU}$, vitamin E 50-100 IU and vitamin K 2.5-5 mg peroral [31]. Surgical methods such as biliary diversion and ileal bypass are also effective in PFIC1-2 patients. In case of therapeutic failure, liver transplantation is required [32]. 
Conclusion

In conclusion, PFIC is typically progressive and may result in cirrhosis and many times end-stage liver disease. It must be differentiated from other causes of cholestasis. Liver transplantation has been accepted as a life saving option for PFIC patients with end-stage liver disease.

\section{References}

1. Jacquemin E. Progressive familial intrahepatic cholestasis. Clin Res Hepatol Gastroenterol 2012; 36: 26-35.

2. Eppens EF, Van Mil SW, De Vree JM, Mok KS, Juijn JA, Oude Elferink RP, et al. FIC1, the protein affected in two forms of hereditary cholestasis, is localized in the cholangiocyte and the canalicular membrane of the hepatocyte. J Hepatol 2001; 35: 436-43.

3. Strautnieks SS, Kagalwalla AF, Tanner MS, Knisely AS, Bull L, Freimer N, et al. Identification of a locus for progressive familial intrahepatic cholestasis PFIC2 on chromosome 2q24. Am J Hum Genet 1997; 61: 630-33.

4. Strautnieks SS, Byrne JA, Pawlikowska L, et al. Severe bile salt export pump deficiency: 82 different ABCB11 mutations in 109 families. Gastroenterology 2008; 134: 1203-14.

5. Gaur K, Sakhuja P. Progressive familial intrahepatic cholestasis: A comprehensive review of a challenging liver disease. Indian J PatholMicrobiol 2017; 60: 2-7.

6. Alissa FT, Jaffe R, Shneider BL. Update on progressive familial intrahepatic cholestasis. J Pediatr Gastroenterol Nutr 2008; 46: 241-52.

7. Scheimann AO, Strautnieks SS, Knisely AS, Byrne JA, Thompson RJ, Finegold MJ. Mutations in bile salt export pump (ABCB11) in two children with progressive familial intrahepatic cholestasis and cholangiocarcinoma. J Pediatr 2007; 150: 556-59.

8. Davit-Spraul A, Fabre M, Branchereau S, Baussan C, Gonzales $\mathrm{E}$, Stieger B, et al. ATP8B1 and ABCB11 analysis in 62 children with normal gamma-glutamyl transferase progressive familial intrahepatic cholestasis (PFIC): Phenotypic differences between PFIC1 and PFIC2 and natural history. Hepatology 2010; 51: 164555.

9. Ramraj R, Finegold MJ, Karpen SJ. Progressive familial intrahepatic cholestasis type 3: Overlapping presentation with Wilson disease. ClinPediatr (Phila) 2012; 51: 689-91.

10. Morotti RA, Suchy FJ, Magid MS. Progressive familial intrahepatic cholestasis (PFIC) type 1, 2, and 3: A review of the liver pathology findings. Semin Liver Dis 2011; 31: 3-10.

11. Arnell H, Fischler B, Bergdahl S, Schnell PO, Jacobsson H, Nemeth $A$. Hepatobiliary scintigraphy during cholestatic and noncholestatic periods in patients with progressive familial intrahepatic cholestasis after partial external biliary diversion. J Pediatr Surg. 2011; 46: 467-72.

12. Srivastava A. Progressive familial intrahepatic cholestasis. J ClinExpHepatol. 2014; 4: 25-36.

13. Knisely AS, Saxena R. Intrahepatic cholestasis: Inherited disorders. In: Saxena R, editor. Practical Hepatic Pathology: A Diagnostic Approach. 1st ed. Philadelphia: Churchill Livingstone; 2011. p. 139-57.

14. Evason K, Bove KE, Finegold MJ, Knisely AS, Rhee S, Rosenthal P, et al. Morphologic findings in progressive familial intrahepatic cholestasis 2 (PFIC2): Correlation with genetic and immunohistochemical studies. Am J SurgPathol 2011; 35: 687-96.

15. Bull LN, Carlton VE, Stricker NL, Baharloo S, DeYoung JA, Freimer
NB, et al. Genetic and morphological findings in progressive familial intrahepatic cholestasis (Byler disease [PFIC-1] and Byler syndrome): Evidence for heterogeneity. Hepatology 1997; 26: 155-64.

16. El-Guindi MA, Sira MM, Hussein MH, Ehsan NA, Elsheikh NM. Hepatic immunohistochemistry of bile transporters in progressive familial intrahepatic cholestasis. Ann Hepatol 2016; 15: 22229.

17. Gonzales E, Spraul A, Jacquemin E. Clinical utility gene card for: Progressive familial intrahepatic cholestasis type 1. Eur J Hum Genet 2014; 22. doi: 10.1038/ejhg. 2013.186.

18. Gonzales E, Spraul A, Jacquemin E. Clinical utility gene card for: Progressive familial intrahepatic cholestasis type 2. Eur J Hum Genet 2014;22. doi: 10.1038/ejhg. 2013. 187.

19. Gonzales E, Spraul A, Jacquemin E. Clinical utility gene card for: Progressive familial intrahepatic cholestasis type 3. Eur J Hum Genet 2014; 22. doi: 10.1038/ejhg. 2013. 188.

20. Sun GR, Burns M. Progressive Familial Intrahepatic Cholestasis: A Rare Cause of Cirrhosis in Young Adult Patients. Case Rep Med. 2015;2015:428638. doi: 10. 1155/2015/428638.

21. Lazaridis KN, Gores GJ, Lindor KD. Ursodeoxycholic acid 'mechanisms of action and clinical use in hepatobiliary disorders'. J Hepatol. 2001; 35: 134-146.

22. Perez MJ1, Briz O. Bile-acid-induced cell injury and protection. World J Gastroenterol. 2009; 15(14): 1677-89.

23. Kotb MA1.Molecular Mechanisms of Ursodeoxycholic Acid Toxicity \& Side Effects: Ursodeoxycholic Acid Freezes Regeneration \& Induces Hibernation Mode. Int J Mol Sci. 2012; 13(7): 8882914.

24. George R1, Stevens A, Berkenbosch JW, et al. Ursodeoxycholic acid in the treatment of cholestasis and hyperbilirubinemia in pediatric intensive care unit patients. South Med J. 2002;95: 1276-79.

25. Thébaut A, Debray D, Gonzales E. An update on the physiopathology and therapeutic management of cholestatic pruritus in children. Clin Res Hepatol Gastroenterol. 2017 Oct 11. pii: S2210-7401(17)30189-4. doi: 10.1016/j. clinre.2017.08.007.

26. Sonthalia N, Jain SS, Pawar VB, et al. A Child with Debilitating Pruritus. ClinPract. 2016; 6: 865. doi: 10. 4081/cp.2016.865.

27. Engelmann G, Wenning D, Herebian D, Sander O, Dröge C, Kluge S, Kubitz R. Two Case Reports of Successful Treatment of Cholestasis With Steroids in Patients With PFIC-2. Pediatrics. 2015;135: e1326-32.

28. Häussinger D, Kordes C. Mechanisms of TauroursodeoxycholateMediated Hepatoprotection. Dig Dis. 2017;35: 224-231.

29. Beuers $U$, Trauner M, Jansen, et al. New paradigms in the treatment of hepatic cholestasis: from UDCA to FXR, PXR and beyond. J Hepatol. 2015; 62(1 Suppl): 25-37.

30. Dolezelova E, Prasnicka A, Cermanova J, et al. Resveratrol modifies biliary secretion of cholephilic compounds in sham-operated and cholestatic rats. World J Gastroenterol. 2017; 23: 7678-92.

31. Yang CH, Perumpail BJ, Yoo ER, et al. Nutritional Needs and Support for Children with Chronic Liver Disease. Nutrients. 2017; 9. pii: E1127. doi: 10. 3390/nu9101127.

32. Englert C, Grabhorn E, Richter A, Rogiers X, Burdelski M, Ganschow R. Liver transplantation in children with progressive familial intrahepatic cholestasis. Transplantation. 2007; 84: 136163. 